\title{
MUNDO DA VIDA: A APROPRIAÇÃO HABERMASIANA DE HUSSERL E WITTGENSTEIN
}

\author{
Nythamar Fernandes de Oliveira**
}

SINTESE - Este artigo apresenta algumas reflexões acerca da concepção habermasiana de mundo da vida, seguindo sua apropriação crítica dos conceitos de Lebenswelt em Husserl e Lebensform em Wittgenstein, de forma a mostrar em que medida Habermas dá conta da fundamentação normativa de uma teoria crítica da sociedade.

PALAVRAS-CHAVE - Normatividade. Racionalidade. Seguir regras. Sociedade. Teoria critica.
ABSTRACT - This article seeks to offer some insights into the Habermasian conception of lifeworld, in light of his critical appropriation of the concepts of Lebenswelt in Husserl and Lebensform in Wittgenstein, so as to show to what extent Habermas succeeds in accounting for the normative grounds of critical theory of society.

KEY WORDS - Critical theory. Following rules. Normativity. Rationality. Society.

Numa pesquisa em andamento apoiada pelo Conselho Nacional de Desenvolvimento Científico e Tecnológico - CNPq, me propus re-examinar a concepção de "mundo da vida" em Habermas, na sua articulação entre autonomia, cultura política e formas de vida social, em contraposição às concepções de "insociável sociabilidade" em Kant e "cultura política pública" em Rawls. Neste artigo, limitarme-ei a tecer algumas reflexões sobre a apropriação habermasiana dos conceitos de Lebenswelt de Husserl e Schütz e de Lebensform de Wittgenstein, na sua tentativa de estabelecer a especificidade metodológica das ciências sociais, seguindo o interesse emancipatório destas ciências (em particular, sociologia política), diferentemente de modelos empírico-analíticos (conforme o interesse técnico das ciências naturais) e modelos histórico-hermenêuticos (interesse prático das ciências culturais e humanas). Em particular, gostaria de rever alguns pressupostos filosóficos inerentes à concepção de mundo da vida em Habermas, na medida em que problematizam seu conceito supostamente pós-metafísico de racionalidade.

* Comunicação apresentada no VIII Encontro Nacional de Filosofia da Assosiação Nacional de PósGraduação em Filosofia - ANPOF, Caxambu-MG, em 26-9-1998; projeto integrado ao grupo de pesquisa "Fenomenologia e Hermenêutica", coordenado pelo Prof. Dr. Ernildo J. Stein.

** Professor de Filosofia da PUCRS e pesquisador do Conselho Nacional de Desenvolvimento Científico e Tecnológico (CNPq). 
Segundo Habermas, a questão da normatividade moral (formulada pela ética do discurso) deve ser articulada com a questão social e política da institucionalização de formas de vida, na própria concepção de um modelo integrado diferenciando o mundo sistêmico das instituições (definido pela capacidade de responder a exigências funcionais do meio social) do mundo da vida (i. é, das formas de reprodução cultural, societal e pessoal que são integradas através de normas consensualmente aceitas por todos os participantes). A hipótese de trabalho que guia minha investigação é mostrar em que medida a concepção habermasiana de mundo da vida logra preservar o conceito kantiano de autonomia num nível público de normatividade e universalizabilidade, ao justificar a integração e diferenciação de instituições, tais como a família, a sociedade civil, o Estado e organizações governamentais e não governamentais, com relação aos subsistemas econômicos, políticos e administrativos. Assim, a facticidade do mundo da vida, em particular, expressa numa cultura política democrática pluralista, deve ser compreendida de maneira correlata à normatividade e validade da autonomia pública, de forma a superar a atual crise paradigmática da democracia, especialmente a crise de legitimação que caracteriza o Estado modemo, sem incorrer nas aporiás de uma crítica da ideologia ou diferentes versões de relativismo, ceticismo e historicismo em filosofia política. Pelo seu procedimentalismo kantiano, a concepção habermasiana de democracia participativo-deliberativa se propõe como uma alternativa aos modelos liberais (especialmente, Rawls) e comunitaristas (neo-aristotélicos, neohegelianos, neo-marxistas). A fim de evitar a auto-referencialidade da razão prática kantiana (o "fato da razão"), Habermas reconcebe a "autonomia pública" como a disponibilidade de uma rede diferenciada de arranjos comunicativos para a formação discursiva da vontade e opinião pública, na medida em que um sistema de direitos individuais básicos fornece exatamente as condições para que as formas de comunicação necessárias para uma constituição do direito politicamente autônoma sejam assim institucionălizadàs. No entanto, apesar de sua construção intersubjetiva do mundo social, à teoria habermasiana parece incorrer em generalizações de concepções empiricas de subjetividade, notavelmente na formulação de uma identidade coletiva, na própria auto-compreensão de cultura em suas dimensões estética, moral e política. Segundo Habermas, os fundamentos necessários para uma autodeterminação capaz de realiżar o projeto modernista de emancipação; embasado na razão e ação comunicativa, deve integrar a vida social cotidiana e exige, portanto, um engajamento da sociedade civil, através da participação política, associações voluntárias, movimentos sociais e desobediência civil, no processo de busca de entendimento mútuo em juizos de validade.

Numa entrevista - originalmente publicada em sueco e holandês - obre "Questões de Teoria Política", ${ }_{1}^{1}$ Habermas nos previne sobre o perigo de interpretarmos o mundo da vida e a ação comunicativa como conceitos complementares, assumindo que o mundo da vida se reproduz através de ações comunicativas, de forma que valores, normas e especialmente 0 uso da linguagem orientada para 0 entendimento mútuo sejam postos sob o fardo da integração apenas numa socie-

1 "A conversation about questions of political theory" in J. HABERMAS, A Berlin Republic: writings on Germany, University of Nebraska Press, 1997, p. 147s. 
dade que satisfaça as exigências intencionalistas de uma socialização comunicativa pura. Segundo Habermas, mesmo com a publicação dos dois volumes de sua Teoria do agir comunicativo ${ }^{2}$ - notavelmente no segundo tomo - sua concepção de integração social tem sido mal entendida como sendo idealista, seja pela alusão a uma "comunidade de comunicação ideal" - que Habermas diferencia de Peircè e Apel - seja pelo uso de uma "situação ideal de fala." Um dos seus críticos e interlocutores mais consistentes; Anthony Giddens, caracterizou o desengate (desconexão, desacoplamento) do sistema e do mundo da vida como uma das contribuiÇões mais notáveis e problemáticas da TKH. Segundo Giddens, se, por um lado, Habermas logra mostrar por que o funcionalismo de teorias sistêmicas não é sustentável assim como não pode ser descartado antes de compreendermos em que consiste a tecnicização do político e suas funções ideológicas, pör outro lado, a distinção habermasiana entre sistema e mundo da vida parece refletir uma diférenciação anterior entre "trabalho" e "interação", sem dar conta dos movimentos sociais que desafiam os mecanismos de controle (steering mechanisms) inerentes a uma concepção funcionalista da sociedade. Em suma, o procedimentalismo habermasiano abrigariá, no seu próprio intuito anti-relativista, uma indesejável versão idealista de funcionalismo. ${ }^{3}$

Mesmo sem entrar nos méritos de questões tão complexas como à da "colonizaçẩo do mundo da vida" ou da "justificação de pretensões de validade em condições ideais" - que guiaram muitas das reformulaçōes posteriores à publicação da TKH - gostaria de proceder a uma breve arqueologia do mundo da vida em Habermas, enfocando em particular Zur Logik der Sozialwissenschaften (1967) e textos intermediários ${ }^{4}$ Como Giddens observou, ZiLS devè ser tonado como os prolegômenos da TKH, no sentido de já haver antecipado todo o trabalho de fundamentação filosớica de uma tèoria social ou, nas palavras de Giddens, "a TKH deveria ser tomada como uma bumper edition da ZLS". Com efeito, ao introduzir o conceito de Lebenswelt em TKH como correlato do agir comunicativo (v. 1, p. 70s.; 108) Habermas nos remete ao esboço metodológico de ZLiS onde se propõe encontrar uma concepção "reconstrutiva da teoria social" - segundo a expressão de Bernstein que Habermas parafraseia (ZLS xiii) - de forma a assinalar o seu projeto como uma alternativa a concepçōes inspiradas da filosofia analítica da linguagem em Wittgenstein, da hermenêutica de Gadamer e da fenomenologia de Husserl e Schütz. Nisso mesmo consistiria a guinada lingüística em teoria crítica na sua tentativa de superar as aporias de uma filosofia do sujeito, segundo a fórmula de Albrecht Wellmer endossada por Habermas neste mesmo texto (Prefâcio à $5^{\mathrm{a}}$ edição de 1982 de ZLS xiii). A preocupação central de Habermas nos anos $60 \mathrm{e}$ 70 pode ser, portanto, caracterizada como uma tentativa de desafiar a hegemonia de concepções empírico-analíticas das ciências sociais, herdando a disputa positivista (Positivismusstreit) opondo Popper e Adorno, mostrando a pertinêncià de estruturas simbólicas e interpretativas na própria formulação do objeto de investi-

2 Em inglês, The theory of communicative action, 2 v., trad. T. McCarthy, Boston: Beacon Press, 1984. Abreviado TKH.

3 BERNSTEIN, Richard J. (org.). Habermas and modernity. Cambridge, Mass.: MIT Press, 1985, p. 119s.

4 Zur Logik der Sozialwissenschaften, abreviado ZLS, remete-nos à versão americana On the logic of the social sciences; trad. S. W. Nicholsen e J. A. Stark, Cambridge: MIT Press, 1989. 
gação social. A magnitude dos estudos empreendidos por Habermas é, desse modo, corretamente qualificada por José Arthur Giannotti como a de um "ecletismo de bricoleur". ${ }^{5}$

Segundo Habermas, as formulações formalizadas das ciências ditas exatas, rigorosas ou naturais não exigem de seus proponentes uma tarefa hermenêutica como parece ser o caso de toda investigação envolvendo documentos, textos e contextos de interpretação. Tanto a abordagem fenomenológico-hermenêutica quanto a lingüístico-analítica partem do problema metodológico de entender o sentido (Sinnverstehen) empiricamente sedimentado como um fato social, através de vivências, tradições e contextos simbólicos complexos. Na recepção sociológica de Husserl e Heidegger, sobretudo do conceito de Lebenswelt do primeiro, Habermas crê haver encontrado os subsídios para a reconstrução de uma experiência comunicativa capaz de ser transformada em dados sociais, mensuráveis como fatos sociais (ZLS 100). Segundo Habermas, os dados a serem medidos devem ser tomados concomitantemente com o seu contexto simbólico, onde são seguidas determinadas regras de ação social comunicativa no mundo da vida cotidiana. A tese central aqui delineada é que dados medidos por diversas técnicas de investigação sociológica pressupõem uma pré-compreensão e uma préinterpretação por parte dos atores sociais (Habermas nos remete aos trabalhos de Kaplan, Coombs, Cicourel e Garfinkel em teoria da sociologia). Esta problemática, segundo Habermas, nos remete a um exame da estrutura transcendental do mundo da vida (no sentido de estabelecer condições de possibilidade de experiência da vida social), tal como Alfred Schütz empreendera nos anos 20 ao usar a fenomenologia de Husserl para abordar problemas de sociologia interpretativa em Max Weber. ${ }^{6}$ Segundo Habermas, a grande contribuição de Schütz consiste em mostrar como o Lebenswelt é "articulado em contextos de significado culturalmente determinados e diferencialmente distribuídos que circunscrevem o âmbito de intencionalidade dentro do qual a ação social pode ocorrer. Tais contextos de significado determinam o âmbito de possíveis projetos de ação e de efetivos esquemas motivacionais de interpretação." Habermas observa en passant que foi inspirandose em Schütz e Herbert Mead que Peter Berger e Thomas Luckmann empreenderam a ambiciosa tarefa de uma "construção social da realidade", The Social Construction of Reality (1966). É precisamente graças a esta articulação do mundo da vida que uma adequada medição de fatos sociais é viabilizada e não excluída ou descartada, como sugerem os positivistas no sistemático eclipse de níveis de intersubjetividade, taken for granted (ZLS 107 s.). Todavia, como seria de se esperar, Habermas crê que as análises de Schütz esbarram em dois problemas intransponíveis, já presentes nas formulações originais de Husserl, a saber, que uma descrição fenomenológica da estrutura transcendental do mundo da vida não dá conta da alteridade da experiência de todo outro, seja um indivíduo ou um grupo social, e que a linguagem ainda não havia sido introduzida como sendo coconstitutiva da intersubjetividade dos atores sociais (ZLS 115-7). Passamos, assim, à abordagem lingüística. 
Segundo Habermas, o problema da linguagem substitui o problema tradicional da consciência, na medida em que "forma de vida" em Wittgenstein corresponde à formulação husserliana de "mundo da vida" não mais através de regras de uma síntese transcendental mas através das regras da gramática de jogos de linguagem. A diferença mais importante entre as abordagens fenomenológicas e lingüístico-analíticas consiste, segundo Habermas, em que a "intersubjetividade não é mais produzida por perspectivas de mundo da vida reciprocamente interligadas e virtualmente permutáveis, mas é dada com as regras gramaticais de interações simbolicamente reguladas. As regras transcendentais de acordo com as quais os mundos da vida são estruturados tornam-se agora compreensíveis através de análises lingüísticas nas regras de processos de comunicação" (ZLS 117). Assim, as ações sociais podem agora ser analisadas do mesmo modo que as relações internas entre símbolos, tornando-as acessíveis a análises empíricas na medida em que são passíveis de descrição, apesar de serem constituídas num nível de proposições acerca de fatos - e não dos próprios fatos. Segundo Habermas, o sucesso das abordagens lingüístico-analíticas das ciências sociais é tributário de dois estágios de autocrítica do positivismo lógico, ambos situados na obra de Wittgenstein. Assim como o Tractatus teria desvelado o estatuto transcendental da linguagem com pretensão de validez científica universal, as Investigações filosóficas teriam mostrado que tal linguagem como tal é uma ficção e que as gramáticas da comunicação pela linguagem ordinária nos revelam regras através das quais formas de vida são constituídas. De resto, Habermas observa que as abordagens fenomenológicas teriam alcançado um êxito maior se a análise transcendental do mundo da vida fosse seguida de uma análise da constituição de mundos da vida específicos, empiricamente existentes. Assim como Husserl, Wittgenstein se serve de analogias com o "horizonte": por exemplo, tudo que é percebido opticamente é dado num campo visual, mas não vemos a perspectiva, a visão corporeamente centrada do olho que vê, "os limites de minha linguagem significam os limites de meu mundo" (Tractatus 5.6) (ZLS 121). Neste sentido, Habermas observa que se, para o primeiro Wittgenstein, proposições normativas não têm lugar num mundo de fatos, na sua concepção tardia "a linguagem monopolista das ciências naturais dá lugar a um pluralismo de linguagens naturais que não mais captam a realidade teoricamente dentro de uma única visão de mundo, mas antes praticamente dentro de diferentes mundos de vida." Segundo tal concepção, "as regras destes jogos de linguagem são as gramáticas tanto de linguagens quanto de formas de vida. Proposições éticas permanecem inexpressivas, mas agora a gramática, que eu posso tornar transparente através de análises lingüísticas, é ela mesma ética, [no sentido de que ela] não é mais a lógica de uma linguagem unitária e do universo de fatos, mas é antes a ordem constitutiva de um mundo da vida social" (ZLS 126). Este é o nível de auto-reflexão sociolingüística que, de acordo com Habermas, caracteriza o segundo estágio das análises lingüísticas. Peter Winch é, assim como Schütz o foi com relação a Husserl, o teórico adotado por Habermas para esgotar o paradigma lingüístico-analítico, nos limites que o conduzem a reexaminar as abordagens hermenêuticas das ciências sociais. Ações sociais são guiadas por regras que não podem ser privadas mas que são intersubjetivamente válidas para uma forma de vida compartilhada por pelo menos dois sujeitos. 0 próprio conceito de "seguir uma regra" no segundo Wittgenstein implica, portan- 
to, a intersubjetividade da validez de regras. ${ }^{7}$ Assim como Habermas aproximarase do conceito comunicativo de poder em Hannah Arendt; sua releitura do Lebenswelt propõe uma combinação deste conceito husserliano com seus homólogos em Wittgenstein, Gadamer, Mead e Austin (speech-act theory). Ambas apropriações passam por uma crítica weberiana do determinismo econômico marxiano. "Mundo da vida" se opõe, portanto, ao "mundo do trabalho capitalista", onde a racionalização societária se traduz em reificação (i. é, a assimilação de relações sociais e experiências subjetivas a coisas, objetos, que percebemos e manipulamos) e se reflete nas crises de integração social, tanto nas esferas do poder quanto nas relações sociais - segundo Habermas, a concepção arendtiana de poder enquanto agir em concerto mascara a questão da violência político-estatal. O mundo da vida complementa, assim, os aspectos econômico-administrativos de uma teoria social, na medida em que são diferenciados os fundamentos da integração social e da integração sistêmica. A crítica habermasiana aos fundamentos filosóficos do paradigma marxiano da produção já fora iniciada em seus primeiros escritos nos anos 60 e 70 (por exemplo, em A transformaçâo estrutural da esfera pública, teoria e práxis, Conhecimento e interesse, Para a reconstrução do materialismo histórico), em particular contra suas concepções de um macro sujeito da história, de um processo unilinear teleológico da história e do funcionalismo instrumentalista da ação, em sua dialética determinista entre forças produtivas e relações de produção. Além de rëformular o problema marxiano do fetichismo mercantil como "colonização interna do mundo da vida" (TKH v. 2, p. 322, 332s.), Habermas acaba por resgatar tanto o aspecto transcendental suprimido pela crítica de Hegel a Kant quanto a complexidade da evolução social da experiência humana. Mundo, nesta acepção fenomenólógico-transcendental, significa horizonte de facticidade e de significação, mundo pré-científico, perspectiva a partir da qual se pode pensar "a totalidade dos objetos de uma experiência possivel e de um conhecimento possível por experiência, a soma dos objetos que, com o fundamento da experiência atual, podem ser conhecidos no quadro do pensamento teórico correto". 8 Ou como Husserl o definiria mais tarde,

"O mundo da vida [Die Lebeinswelt] está desde sempre lá [immer schon da], sendo para nós, de antemão, fundamento para qualquer um, seja na prática teórica ou na práxis extrateórica. $O$ munido nos é dado de antemão, a nós despertos, que somos sempre de algum modo sujeitos com interesse prático... [o mundo] nos é dado como campo universal de toda práxis efetiva e possivel, dado de antemão como horizonte."9

Para além de todas as analogias entre Husserl e Wittgenstein e suas respectivas apropriações em Schütz e Winch, gostaria de retomar dois problemas que, creio eu, não foram devidamente desenvolvidos por Habermas em seus escritos sobre esses autores, a saber: 1) o mundo da vida em Husserl, por ser um conceito ambíguo e de significação apenas esboçada, longe de ter sido conclusivo para

7 Cf. OLIVEIRA, Nythamar Fernandes de. Significado e Skepsis nas Investigações de Wittgenstein. Veritas, Porto Alegre, PUCRS, 41/161, 1996, p. 65-74.

8 Cf. HUSSERL, E. Ideen zu einer reinen Phänomenologie und phänomenologischen Philosophie, Erstes Buch (Husserliana III). Haia: M. Nijhoff, 1976, p. 8.

9 HUSSERL, E. Die Krisis der europäischen Wissenschaften unid die transzendentale Phänomenologie (Husserliana VI). Haia: M. Niłhoff, 1976, p. 145. Abreviado K. 
uma fenomenologia do mundo social, deveria apenas ser tomado como ponto de partida para reflexões futuras, inclusive na direção assumida pela hermenêutica, tanto na interpretação de mundo como horizonte em Heidegger, como na de seu discípulo Gadamer e nos trabalhos de Merleau-Ponty e Ricoeur; 2) há problemas inerentes à leitura que Habermas nos oferece de Wittgenstein, tanto na sua oposição entre o primeiro e o segundo Wittgenstein quanto na confluência entre este e a tradição fenomenológico-hermenêutica, como já assinalara Giannotti no artigo supracitado e em sua obra seminal sobre a Apresentação do mundo. ${ }^{10}$

I - Como observa Anthony Steinbock no seu magnífico estudo sobre fenomenologia generativa depois de Husserl, o termo Lebenswelt foi empregado pela primeira vez por Husserl no segundo livro das Idéias, de 1916-17, num apêndice ao parágrafo 64 , acerca da primazia do espírito (absoluto) sobre a natureza (relativa) (Ideen II, p. 384, cf. 302 n: ). ${ }^{11}$ Lebenswelt é usado aqui para caracterizar o mundo comunicativo pessoal, o mundo natural, o mundo intuitivo e o mundo estético da experiência, em oposição a concepções naturalistas e objetivas das ciências naturais. Lebenswelt, nesta acepção, é tomado como equivalente a Umwelt (mundo ambiental/circundante), Alltagswelt (mundo cotidiano), Erfahrungswèlt (mundo da experiência) e o conceito natural de mundo (natürlicher Weltbegriff), que Husserl reconhecidamente empresta de Richard Avenarius. Mas é notavelmente no texto de Krisis (1. ed. 1954; 2. ed. 1993) dos anos 30 que Husserl nos fornece pelo menos quatro conceitos provisórios de mundo da vida:

1. mundo da vida é o que pode ser intuído

2. o fundamento do sentido

3. o reino das verdades relativas-subjetivas

4. o mundo da vida enquanto estrutura essencial, ou como o mundo perceptual (eidos).

Segundo Steinbock, estes conceitos de Lebenswelt são provisórios nả medida em que são ontológicos ou pertencem a uma fenomenologia estática (näo genética, não generativa) e devem ser diferenciados dos conceitos transcendentais de Lebenswelt como horizonte e como fundamento. Pode-se falar, neste sentido, de seis conceitos distintos de Lebenswelt em Husserl. As quatro concepções preliminares de mundo da vida em Krisis, segundo Steinbock, são irredutíveis a um único conceito e não possibilitam que falemos de uma teoria coerente, unívoca, do mundo da vida em Husserl, pelas seguintes razões:

1. O ponto de partida de Krisis é que Kant teria deixado de examinar os pressupostos das ciências objetivas. Assim, o mundo da vida pode ser compreendido como este pressuposto não tematizado, o mundo circundante cotidiano enquanto fonte de evidência. Neste sentido, o mundo da vida tem primazia epistemológica por ser intuível, numa experiência prélingüística, pré-conceitual, pré-predicativa que precede toda conceitualização. O mundo da vida é, portanto, concebido como o mundo précientífico imediatamente dado (cf. K 106).

10 GIANNOTTI, J. A. Apresentação do mundo. São Paulo: Cia. das Letras,1995.

11 STEINBOCK, A. Home and beyond: generative phenomenology after Husserl, Evanston, Ill.: Northwestern, 1995. 
2. Numa segunda concepção o que está em jogo é a função relacional entre o intuível e o não intuível. Assim Lebenswelt é descrito como fundamento de sentido (Sinnesfundament) para as ciências, i. é, fornecendo a base intuitiva dos objetos e proposições científicas.

3. Como não há uma maneira de discriminar entre mundos da vida seja em termos da prioridade de sentido ou de alguma característica comum compartilhada por vários sujeitos - i. é, minhas verdades objetivas fazem sentido dentro do meu mundo da vida assim como as dos outros nos seus respectivos mundos da vida - é inevitável chegarmos a uma concepção de uma pluralidade de mundos da vida (K 134; 141). O que há de mais interessante aqui é que Husserl já introduz deste modo uma concepção não hierárquica de mundos da vida como mundos culturais. Steinbock observa com razão que seria errôneo pensarmos que teríamos aqui uma teoria da intersubjetividade em Husserl. Uma ontologia do mundo da vida permanece provisória, assim como provoca o pensamento de um possível relativismo cultural e de um relativismo histórico.

4. É precisamente neste nível que o relativismo é superado na medida em que a estrutura do mundo da vida desvela sua "universalidade concreta", através do processo de redução eidética, exigindo assim uma validade intersubjetiva, uma objetividade comum a todos (K 142). Neste sentido, Husserl afirma que as ciências objetivas têm as mesmas estruturas que 0 mundo da vida pré-científico, embora aquelas apenas pressuponham tais estruturas eidéticas e as abandonem em sua busca sistemática de verdades teóricas para saberes específicos.

Segundo Husserl, uma ontologia do mundo da vida é realizada sem nenhum interesse transcendental, na atitude natural (i. é, na at'tude ingênua, anterior ao epoche; K 176). Deste modo, uma ontologia do mundo da vida deve ser diferenciada de uma análise transcendental do mundo da vida (Cf. parágrafos 37 e 51 de Krisis). A grande tarefa husserliana de proceder a uma teoria da essência do mundo da vida (K 145) consiste em elucidar os conceitos transcendentais da $\mathrm{Le}$ benswelt, nas suas modalidades de "território" enquanto horizonte do mundo (Welthorizon) e fundamento da terra (Erdeboden). Se, numa perspectiva cartesiana, o mundo da vida é essencialmente abordado como mundo, i. é, totalidade, ou como fenômeno intencional puro (e. g. K 177), talvez isso fique evidenciado pelo tratamento que recebe enquanto "objeto" ou como "corpo físico" (Körper). Afinal, o mundo enquanto totalidade sintética é, para Husserl, correlato de universalidade de realizações conectadas sinteticamente (K 148). A fenomenologia deve tratar de entes na sua totalidade, como mundo. Nisto mesmo consiste o papel epistêmico da fenomenologia, enquanto philosophia prima que se opõe a doxa, portanto, frente à totalidade do mundo. Assim, do mundo pode-se passar ao objeto, ao mundo mesmo como objeto, na medida em que mundo tem uma estrutura - do ponto de vista fenomenológico - de objeto (Ideen I, p. 10, 390; § 49, 114).

Segundo Steinbock, a abordagem transcendental do mundo poderia ser assim sumarizada: 
1. O mundo é pressuposto como tendo a mesma estrutura de um objeto.

2. Numa perspectiva fenomenológica, isso significa que o mundo torna-se um correlato da vida intencional (como numa análise cartesiana do mundo).

3. O mundo se torna uma unidade abrangente, telos e arche, uma única força constitutiva.

4. Precisamente enquanto mundo futural, baliza o desenvolvimento do sentido unitário de todos objetos, comunidades e culturas.

5. Em última análise, não haveria mais a possibilidade de se encontrar um mundo radicalmente outro, i. é, um Heimwelt implicaria todo possível Fremdwelt, na medida em que eles são co-constituídos em modalidades opostas (normal e anormal) de constituição de sentido.12

Ao sairmos de uma ontologia do mundo da vida, estaríamos assim abandonando o mundo ôntico da atitude natural em direção a uma análise transcendental do mundo da vida como horizonte e fundamento, i. é, examinando não mais o que o mundo da vida é mas como, enquanto mundo da vida, ele está desde sempre em jogo.

II - Contrariamente à leitura que Habermas faz de Winch, David Bloor mostrou que a concepção coletivista (community-based) de linguagem no segundo Wittgenstein é bem sucedida nos seus três argumentos correlatos:

1. Uma regra é uma instituição social.

2. Seguir uma regra é participar de uma instituição social.

3. Uma instituição pode ser analisada em termos de processos coletivos tendo um caráter auto-referencial ou performativo. ${ }^{13}$

Nos seus Remarks on the Foundations of Mathematics, Wittgenstein já mostrara que seguir uma regra é uma atividade humana (VI-29, p. 331), que a linguagem nos remete a um modo de vida (VI-34, p. 335) e que, em última análise, se não somos compelidos por uma regra é porque não estamos seguindo uma regra (VII-47, p. 413). ${ }^{14} \mathrm{O}$ conceito de Lebensform é usado nas Investigaçöes num sentido que corrobora essas premissas, afirmando tanto o embasamento sócioinstitucional das regras quanto seu caráter infinito e normativo derivado de seu significado. Nisto mesmo consiste, segundo Bloor, o determinismo e firitismo de significado (meaning determinism/finitism) em Wittgenstein, no sentido de constatar que o significado, pelo que pressupõe no uso e treinamento inerentes a uma forma de vida, é um fenômeno social. Assim como não há linguagem sem jogo de linguagem, o uso de linguagens é fundado em situações, contextos, meios de vida humana: "imaginar uma linguagem significa imaginar uma forma de vida (eine Sprache vorstellen heisst, sich eine Lebensform vorstellen)"15 (PU § 19). Para Wittgenstein, problemas filosóficos surgem precisamente quando a linguagem

\footnotetext{
12 Cf. A. Steinbock, op. cit., p. 179.

BLOOR, D. Wittgenstein, Rules and Institutions. London and New York: Routledge, 1997; cf. Wittgenstein: a social theory of knowledge, London: MacMillan, 1983.

Trad. G. E. M. Anscombe, Cambridge, Mass.: MIT Press, 1991.

15 L. Wittgenstein, Philosophische Untersuchungen, ed. bilingüe, trad. G. E. M. Anscombe, New York: MacMillan, 1958. Abreviado PU.
} 
entra em férias (when language goes on holiday, § 38), pois "o falar da linguagem [das Sprechen der Sprache] é parte de uma atividade [Tätigkeit] ou de uma forma de vida [Lebensform]" (PU § 23). A metáfora do jogo de linguagem (Sprachspiel) é, portanto, correlata ao significado que emerge do fluxo da vida e do pensamento. ${ }^{16}$ Quando se trata de pressupor um "acordo na linguagem", para Wittgenstein este é um "acordo não em opiniões mas na forma de vida" (PU § 241), na medida em que "o que tem de ser aceito, o dado [das Hinzunehmende, Gegebene] são formas de vida" (PU II xi 226). Assim, "uma intenção [de significado] está incrustada na sua situação, costumes e instituições" (PU § 337). É neste mesmo contexto de Lebensform que podemos entender a intrigante suposição de que "se um leão pudesse falar, eu não poderia entendê-lo [Wenn ein Löwe sprechen könnte, wir könnten ihn nicht verstehen]" (PU II xi 223). De acordo com o finitismo de significado em Wittgenstein (meaning finitism), as fontes de constrangimento são condições locais impostas sobre nós: nossos instintos, nosșa natureza biológica, nosso senso de experiência, nossas interações com outras pessoas, nossos alvos imediatos, nosso treinamento (Abrichtung), etc., começando com as causas psicológicas e terminando com as causas sociológicas. ${ }^{17} \mathrm{~A}$ instituição social da linguagem se revela, portanto, num padrão coletivo de atividade auto-referencial, na própria prática de seguir regras.

Partindo da distinção wittgensteiniana entre as regras de um jogo de linguagem e seus modos de apresentação (PU § 50), Giannotti já havia sugerido que examinássemos a metáfora do "contrato social" em termos de regras e dos jogos de linguagem ai implicados. ${ }^{18} \mathrm{~A}$ idéia de normatividade (por exemplo, na concepção kantiana, onde o contrato é articulado em termos procedimentais com o imperativo categórico) não deve, pois, ser confundida com o consenso exigido pela concepção de um contrato originário -sem dúvida, este é outro ponto de divergência entre Rawls e Habermas. Se o contrato implica promessas, estas já são institucionalizadas: agentes se comprometem a seguir regras e estas devem ser conhecidas e reconhecidas publicamente. Como Giannotti observa, num outro contexto,

"Existe sempre, entre os individuos que seguem uma regra um espaço de indefinição: só os resultados mostram o bom entendimento e até onde a regra é consenso. Isto significa que não há consenso antes dum acordo prático sobre os resultados, que se tece durante o próprio juízo. Não há entendimento (Verständigung) por meio da linguagem que se reduza a uma proposta comum feita por definições. Antes que os atores empreguem efetivamente os critérios acordados não é possivel nem mesmo saber se compreenderam o sentido desses critérios. Neste ponto, sentido se cruza com o aprendizado." (PU § 242) ${ }^{19}$

16 Cf. L. Wittgenstein, Zettel, Oxford: Blackwell, 1967, p. 173: "Only in the stream of thought and life do words have meaning."

17 Cf. D. Bloor, Wittgenstein, rules and institutions, op. cit., p. 20.

18 J. A. Giannotti, "Contrato e contrato social", Filosofia política 6, 1991, p. 9-29.

19 Giannotti, "Habermas: māo e contra-mão", art. cit.,p. p. 11s. 
Esta citação de Giannotti aponta para uma confluência tão importante quanto problemática entre o segundo Wittgenstein e a hermenêutica mundana de Heidegger, Merleau-Ponty e Gadamer, num ponto-cego da reflexão habermasiana que se propõe a mostrar que "trabalho e linguagem são anteriores ao homem e à sociedade" (Reconstrução 118). Como observa Giannotti, se para Wittgenstein "o mundo se apresenta pela linguagem é porque esta falha em representá-lo por inteiro". Heidegger e Merleau-Ponty, ao contrário, parecem restringir a linguagem, na esteira de Husserl, a uma doutrina da expressão antepredicativa. Nas palavras de Giannotti,

\begin{abstract}
"Enquanto Wittgenstein dirá que basta descrever o jogo de linguagem pelo qual podemos exprimir o ver e o sentir, Heidegger, seguido por Merleau-Ponty, recua para um plano pré-lógico onde o compreender se resolve no esforço de apreender um sentido se expressando no nível das próprias coisas e de nossa abertura para o mundo. Em suma, se no final de contas é num remetimento ao Lebenswelt que se cruzam as investigações fenomenológicas com aquelas da filosofia analítica, isto se faz por caminhos inteiramente divergentes, em particular no que concerne ao núcleo da própria questão da racionalidade."20
\end{abstract}

Em última análise, para Giannotti, são "a duplicidade duma teoria da expressão e uma teoria da linguagem predicativa" que constituem o verdadeiro impedimento para que o legado fenomenológico possa dar conta de "jogos de linguagem não verbais" numa tentativa de se transpor as aporias do esquema operatório inerente ao paradigma marxiano da produção, que Habermas pretende substituir por uma concepção pragmático-universal do mundo da vida. Se Wittgenstein preserva o princípio da duplicidade, nem por isso "o mundo é redutível a um mundo pensável": "todo jogo de linguagem é um pensamento", mas "o fato da expressão já reside no mundo cotidiano". ${ }^{21}$ Richard Bernstein, que já em 1961 aproximara Wittgenstein da tradição semiótico-pragmática de Peirce, sugere que problematizemos a oposição entre os projetos do Tractatus e das Investigações e abandonemos toda tentativa de encontrar uma suposta chave hermenêutica dando conta da crítica do segundo à "linguagem logicamente perfeita" do primeiro, onde encontramos, na verdade, três concepções de linguagem permeiando a articulação de sentido do mundo:

"Pelo menos três linguagens são distinguidas no Tractatus: a linguagem perspicaz, a linguagem ordinária e a linguagem da escada [perspicuous, ordinary and ladder languages]. A linguagem perspicaz é uma [ferramenta] de ajuda para compreendermos como a linguagem funciona quando a usamos para fazer enunciados verdadeiros e falsos. Não é uma linguagem ideal da qual a linguagem ordinária deve 'aproximar-se' ['approach'] a fim de cumprir sua função. Para descrever tal linguagem perspicaz devemos usar uma linguagem - a linguagem da escada - que não deve ser confundida com a linguagem objeto que descreve: as 'proposiçöes' na linguagem da escada não podem ocorrer na linguagem perspicaz." 22

20 Giannotti, Apresentação do mundo, op. cit., p. 17.

21 Ibidem, p. $16 \mathrm{~s}$.

22 BERNSTEIN, R. Wittgenstein's three languages. Review of Metaphysics, 1961, p. 284. 
Bernstein, assim como Giannotti, em se apoiando nos Notebooks, observará que a tentação a que sucumbe Habermas de passarmos ao modelo de jogos de linguagem para simplesmente superarmos a generalização da teoria figurativa do Tractatus e assegurarmos assim um fundo de consenso normativo imbricado em todo agir comunicativo trai, na verdade, um retorno a uma estrutura regulativa ideal, "quase-transcendental", que persiste em sua aproximação das formas do mundo social via Peirce, Austin e Searle. ${ }^{23} \mathrm{O}$ abandono do solipsismo em favor do jogo de linguagem nos propõe antes a tarefa, segundo Giannotti, de pensar como é que "leis lógicas, gramaticais, atemporais podem relacionar-se com estruturações empíricas, temporais, sem que se tome o caminho fácil quer de negar a especificidade normativa dessas leis quer de recorrer a uma espécie de facticidade originária donde o eidético pudesse ser retirado a golpes de viradas de consciência". ${ }^{24}$ Giannotti critica Habermas por se socorrer "de um sistema de referência fixo e formalizável", ao contrário da gramática wittgensteiniana que "enraíza seus fundamentos numa práxis mutável, cuja fixidez do modo particular e determinado de agir diferencia-se conforme os niveis do conhecimento." Nisto consiste precisamente o recurso final à linguagem cotidiana: "apelar para uma forma de vida, que vale basicamente como forma". ${ }^{25}$ Assim, Giannotti conclui que o agir (Handeln), para além de todas as diferenças de formas de vida, não está fundamentado num nível transcendental nem empírico de jogos de linguagem, precisamente por não se tratar de um "agir comunicativo" mas é fundamento (Grund) dele mesmo, enquanto Tat originário:

"Agir portanto perspectivando-se, em consequiência, abrindo o espaço lógico onde outras perspectivas possam ocorrer. Ora, se uma perspectivação, ligada à maneira de se lidar com os meios de apresentação, desenha um espaço onde o indubitável, o sim e o não se tornam operantes, entre uma perspectiva e outra, a despeito de, nesse interstício, ser impossivel o funcionamento de qualquer tipo de bipolaridade, fica aberta a possibilidade dum começo de entendimento (Verständigung). ".26

Vimos que o grande desafio de repensar o mundo da vida, segundo Habermas, é dar conta da oposição entre uma perspectiva interpretativa do agente que assume pretensões de validade e a perspectiva da realidade social, simbolicamente pré-estruturada, cuja lógica interna se torna objeto da investigação sociológica (TKH v. 1, p. 107). Com efeito, segundo Kenneth Baynes, a leitura habermasiana de mundo da vida parece situar-se a meio caminho entre a noção de harmonia pré-estabelecida entre filosofia e ciências sociais de Schütz e a noção de envolvimento recíproco em Merleau-Ponty. ${ }^{27}$ Habermas se serve, portanto, de maneira estratégica do conceito de mundo da vida, aproximando-o de formas de vida social que traduzam a normatividade do agir comunicativo no espaço público

23 Cf. BERNSTEIN, R. The restructuring of social and political theory. Philadelphia: University of Pennsylvania Press, 1976, p. 185-233.

24 Giannotti, Apresentaçãodo mundo, op. cit., p. 269.

25 Ibid., p. 251.

26 Ibid., p. 273

27 BAYNES, K. Crisis and life-world in Husserl and Habermas. In: DALLERY, A., SCOTT, C., ROBERTS, Albany (orgs.). Crises in continental philosophy. New York: Suny Press, 1990, p. 59. 
onde se reconhece a operacionalidade institucional de seguir regras. Apesar de problematizar a noção de complementaridade entre mundo da vida e agir comunicativo em seus escritos mais recentes, Habermas mantém alguns dos paradoxos e aporias inerentes às formulações originais de Lebenswelt em Husserl e Lebensform em Wittgenstein. Sua tentativa de lingüistificação de uma sociabilidade préteórica parece trair um ideal de fundamentação da razão instrumental sobre um modelo de razão comunicativa. Na medida em que Habermas, como bem observou Bernstein, continua repensando e reescrevendo a Dialética do esclarecimento a fim de levar a cabo as promessas de emancipação deste projeto inacabado, 28 resta-nos acreditar na dimensão utópica de seu ambicioso programa de ação comunicativa.

28 Cf. BERNSTEIN, R. An allegory of modernity/postmodernity: Habermas and Derrida. In: The New Constellation. Cambridge, Mass.: MIT Press, 1996, p. 207. 